\title{
Assessment of genetic diversity for biomass related traits in Sweet Sorghum (Sorghum Bicolor (L.) Moench.)
}

\author{
D.M. Bahadure ${ }^{1 *}$, S. Marker ${ }^{2}$, A.V. Umakanth ${ }^{3}$, Prabhakar $^{4}$, J. V. Patil ${ }^{5}$, \\ And G. J. Synrem ${ }^{6}$ \\ I*: Ph.D. Scholar, Dept. of GPB, SHIATS, Allahabad-211007 (U.P.) \\ ${ }^{2}$ Associate Professor and Head, Dept. of GPB, SHIATS, Allahabad \\ ${ }^{3}$ Principal Scientists, Directorate of Sorghum Research, Rajendranagar, Hyderabad (A.P.) \\ ${ }^{4}$ Principal Scientist and Officer-in-charge, Centre on Rabi Sorghum, Solapur, Maharashtra \\ ${ }^{5}$ Director, Directorate of Sorghum Research, Rajendranagar, Hyderbad \\ ${ }^{6}$ Ph.D Scholar, Dept. of GPB, SHIATS, Allahabad
}

\begin{abstract}
Thirty five sweet sorghum genotypes of diverse origin were subjected to multivariate analysis. Depending on the $D^{2}$ values, these were grouped in to six clusters. Cluster II was the largest and consisted of 10 genotypes and cluster VI was the least with one genotype. The inter-cluster distances were higher than the intracluster distances reflecting wider genetic diversity among the genotypes. Based on the $D^{2}$ values, the genotypes from diverse clusters would be derived and used in the hybridization program to generate wide range of transgressive segregants for sweet sorghum improvement.
\end{abstract}

Key words: Cluster distance, genetic diversity, sweet sorghum.

\section{Introduction}

Plant biomass has been known for decades as one of the most promising renewable energy source that can be used for production of biofuel, since it is an abundant resource, has low $\mathrm{CO}_{2}$ emissions and low cost. Biomass provides approximately $14 \%$ of the total world-wide energy needs and represents an important contributor to world economy. Furthermore, plant biomass can contribute to a stabilization of farmer's incomes, and can maintain and improve ecological and social sustainability. One of the prime sources investigated as energy crops is sweet sorghum. It was found to contain $43.6-58.2 \%$ soluble sucrose, glucose and fructose in the stalk and $22.6-47.8 \%$ insoluble cellulose and hemicellulose (Ya Lizhao et al. 2009). Sweet sorghum is tall, with high biomass and juicy stem and most importantly contain high stem sugar concentration. Sweet sorghum is closely related to sugarcane and the commercial value of these crops are based on exploiting their stems when contain high amount of sugar (Harlan and Dewet 1972). The national biofuel policy of 2009 aims at promoting biofuels to meet India's energy needs in an environmentally sustainable manner, while reducing its import dependence on fossil fuels. The policy also proposed an indicative target of 20 per cent blending of ethanol by 2017 from the current 10 per cent ethanol blending with petrol. The traditional route of ethanol production through sugarcane molasses would not be meeting this huge demand because of the difficulties in increasing the sugarcane area beyond the current 4.4 million ha in the country.

Success of any crop breeding programme is based on the knowledge of and availability of genetic variability for efficient selection. Genetic similarity or genetic distance estimates among genotypes are helpful in selecting parental combinations for creating segregating population so as to maintain genetic diversity in a breeding programme and the classification of germplasm into heterotic groups can be based for hybrid crop breeding. Sorghum is endowed with high variability due to its wide range of adaptation in tropical and temperate climate and free gene exchange among various races. An attempt in the present study has been made to study the nature and magnitude of genetic divergence for key biomass related traits to identify suitable parents for devising an efficient sweet sorghum improvement program.

\section{Materials And Methods}

Thirty five diverse sweet sorghum genotypes from national programme having different geographical origins and representing the spectrum of variation were evaluated in a Randomized Block Design with three replications at the Research Farm, Centre on Rabi Sorghum (DSR), Shelgi Solapur during kharif, 2011. Each entry had two rows each of $4 \mathrm{~m}$ length with row to row spacing being $60 \mathrm{~cm}$ and plant to plant spacing of $15 \mathrm{~cm}$. All the recommended agronomic practices were followed to raise a good crop. Five randomly selected plants from each line were used for recording observations on four biometrical traits viz, plant height $(\mathrm{cm})$, total biomass yield (t/ha), fresh stalk yield (t/ha) and grain yield ( $\mathrm{kg} / \mathrm{ha})$. 
The data was subjected to statistical analysis. Wilk's criterion was used to test the significance of pooled differences in mean values for all the six characters. Genetic diversity was studied using Mahalanobis (1936) $\mathrm{D}^{2}$ statistics and clustering of genotypes was done according to Tocher's method.

\section{Results And Discussion}

The results obtained under the present investigation are presented in Tables 1-3.

The analysis of variance showed highly significant differences among genotypes for all the biomass characters studied indicating the existence of considerable amount of variability in the experimental material. The present findings corroborate the earlier reports of Almodares and Mostafafi (2006), Almodares et al. (2008), that many characteristics such as biomass yield, grain yield and plant height have been proved as major contributors to economic yields in sweet sorghum.

Multivariate analysis based on Mahalanobis $\mathrm{D}^{2}$ statistics revealed that the genotypes could be grouped in to 6 clusters (Table 1). Cluster II was the largest and consisted of 10 genotypes followed by clusters III, IV and I each having 9, 7 and 6 genotypes respectively. Cluster VI had only 1 genotype. It was gratifying to note that group II included germplasm from world collection. Cluster III included genetic stocks developed in the Indian national program. The pattern of group constellation proved the existence of significant amount of variability, appreciable genetic divergence in sweet sorghum has been earlier reported by Elangovan (2013), Bala Ravi et al. (1997) and Allard, R.W. (1960).

The cluster means estimated over the genotypes for four characters are presented in Table 2. Cluster IV $(325.52 \mathrm{~cm})$ and cluster-I $(325.23 \mathrm{~cm})$ had the highest mean values for plant height. With respect to total biomass, the genotypes with highest mean value were in cluster-I (70.78) and cluster-IV (53.45). Similar trend was observed for fresh stalk yield cluster-I (52.04) and cluster-IV (36.64). Highest grain yield was recorded in cluster-I (2984.30), followed by cluster-III (2942.36) and cluster-IV (2553.68). According to cluster mean values, the cluster-IV and cluster-I had promising genotypes for important traits.

The intra and inter cluster $\mathrm{D}^{2}$ values among 35 genotypes are presented in Table 3 . The average intra cluster distance ranged from 158.68-518.25. The maximum intra cluster distance was recorded for cluster-III (518.25) followed by cluster-IV (422.03) indicating the existence of diverse cultivars in these groups. Whole minimum intra cluster distance was recorded in cluster-VI $(0.00)$. This suggests that genotypes occupying the same cluster have little diversity and selection of parents from within the cluster may not be considered promising for getting good segregants through hybridization programme (Goel et al. 2005). The average intercluster distance range was wide varying from 496.93 to 3320.55 . The inter-cluster $\mathrm{D}^{2}$ value was found maximum (3320.55) between cluster-I and VI followed by cluster-I and II (3140.06) and cluster-IV and clusterVI (2578.94) indicating that the genotypes included in different clusters could give high heterotic response and better segregants after hybridization. These results are in conformity with the findings of Elangovan et al. (2013). Clustering pattern observed from the present study reveals that genetic diversity was not necessarily parallel to geographic diversity. Genotypes evolved in the same area were grouped into different clusters. Similar result was reported by Kadam et al (2001). Maximum heterosis is expected from crosses with parents belonging to most divergent clusters. Genotypes from clusters-II, IV and cluster-III may be used as parents for hybridization programme as heterosis can be best exploited and chances of getting transgressive segregants are maximum when genetically diverse genotypes are crossed.

All these parents can be used in sweet sorghum cultivar development programs to address ethanol production from juice without compromising on grain yields and offer solution to the ongoing food vs fuel debate.

\section{Acknowledgements}

The Authors are sincerely grateful to Hon'ble Director, Directorate of Sorghum Research, Rajendranagar, Hyderabad and Hon'ble Vice-Chancellor, Sam Higginbottom Institute of Agriculture, Technology and Sciences, Allahabad, for providing necessary facilities for completing the research work.

\section{References}

[1]. Allard, R.W. 1960. Principles of Plant Breeding. New York: John Willey and Sons. 485p.

[2]. Almodares, A., and Mostafafi, D.S.M. 2006. Effects of planting date and time of nitrogen application on yield and sugar content of sweet sorghum. Journal of Environmental Biology 27: 601-605.

[3]. Almodares, A., Taheri, R., and Adeli S. 2008. Stalk yield and carbohydrate composition of sweet sorghum (Sorghum bicolor (L.) Moench) cultivars and lines at different growth stages. Journal of Malaysian Applied Biology 37: 31-36.

[4]. Bala Ravi, S., Biswas, P. K., and Ratnavathi, C.V. 1997. Genetic variability and stability for the major traits of sweet sorghum. Proceedings of first International Sweet sorghum conference, 298-300.

[5]. Elangovan, M., Kiran Babu, P., Seetharama, N and Patil J.V. 2014. Genetic diversity and heritability characters associated in sweet sorghum (Sorghum bicolor (L.) Moench). Sugar Tech 16:(2) 200-210

[6]. Goel, P., Swati Sharma, P.K., and Srivastava, K. 2005. Genetic divergence in an elite germplasm collection of wheat (Triticum spp.). Crop Improvement 32: 114-120. 
[7]. Harlan, J.R., and Dewet, J.W.J. 1972. A simplified classification of sorghum. Crop Science 12: 172-176.

[8]. Kadam, D.E., Patil, F.B., Bhor, T.J. and Harer P.N. 2001. Genetic diversity studies in sweet sorghum. J.Maharashtra agric. Univ. 26 (2) : 140-143.

[9]. Ya Li Zhao, Abdughani Dolat, Yosef Steinbergers, Xin Wang, Amarjan Osman and Guang Hui Xie. 2009. Biomass yield and changes in chemical composition of sweet sorghum cultivars grown for biofuels. Field Crop Research, 111 (1): 55-64

Table-1: Distribution of 35 genotypes of Sweet Sorghum into different clusters

\begin{tabular}{|c|l|c|}
\hline Cluster No. & \multicolumn{1}{|c|}{ Name of genotypes included } & \multicolumn{1}{|c|}{$\begin{array}{c}\text { No. of } \\
\text { genotypes }\end{array}$} \\
\hline I & RSSV76, RSS-120, RSSV-9, M-11, DSR-29, DSR-49 & 6 \\
\hline II & $\begin{array}{l}\text { IS-21887, IS-28090, IS-1006B, 24B, NSSB-1007, PMS-71 B, NSSB-23B, ICSB-675, NSSB- } \\
\text { 8, NSSB-1016 }\end{array}$ & 10 \\
\hline III & DSR-46, DSR-45, DSR-48, URJA, DSR-35, DSR-43, RS-647, SSV-84 & 9 \\
\hline IV & DSR-21, IS-6962, RSSV-138-1, UK-81, CSV-19SS, DSR-47, SSV-74 & 7 \\
\hline V & RS-1220B, NSSB-10 & 2 \\
\hline VI & RED-X & 1 \\
\hline
\end{tabular}

Table-2: Cluster mean values for different contributing characters

\begin{tabular}{|c|c|c|c|c|c|c|c|}
\hline \multirow{2}{*}{$\begin{array}{l}\text { S. } \\
\text { No. }\end{array}$} & \multirow{2}{*}{ Characters } & \multicolumn{6}{|c|}{ Clusters } \\
\hline & & I & II & III & IV & $\mathbf{V}$ & VI \\
\hline 1 & Plant height $(\mathrm{cm})$ & 325.23 & 163.12 & 295.09 & 325.52 & 221.83 & 190.00 \\
\hline 2 & Total biomass yield $\left(\mathrm{t} \mathrm{ha}^{-1}\right)$ & 70.78 & 14.56 & 30.77 & 53.45 & 41.82 & 10.35 \\
\hline 3 & Fresh stalk yield $\left(\mathrm{t} \mathrm{ha}^{-1}\right)$ & 52.04 & 07.92 & 19.01 & 36.64 & 23.01 & 06.82 \\
\hline 4 & Grain yield $\left(\mathrm{kg} \mathrm{ha}^{-1}\right)$ & 2984.03 & 1957.58 & 2942.36 & 2553.68 & 2266.87 & 1061.83 \\
\hline
\end{tabular}

Table-3: Average Intra and inter-cluster distance $\left(\mathrm{D}^{2}\right)$ for 35 Sweet Sorghum germplasm (Ward's method 1963)

\begin{tabular}{|c|c|c|c|c|c|c|}
\hline Cluster & I Cluster & II Cluster & III Cluster & IV Cluster & V Cluster & VI Cluster \\
\hline I & 158.68 & 3140.06 & 1273.45 & 496.93 & 1239.29 & 3320.55 \\
\hline II & & 343.27 & 1492.47 & 2410.44 & 779.59 & 826.22 \\
\hline III & & & 518.25 & 826.45 & 980.92 & 1570.05 \\
\hline IV & & & & 422.03 & 1008.68 & 2578.94 \\
\hline V & & & & & 335.89 & 1429.9 \\
\hline VI & & & & & & 0 \\
\hline
\end{tabular}

